\title{
Classroom Process and Learning Achievement of MLE and Non- Mle Schools of Keonjhar District
}

\author{
Dr. Ranjan Kumar Rout \\ Assistant Professor, PG Department of Education \\ F.M University, Vyasa Vihar, Balasore, Odisha
}

\begin{abstract}
NEP, 2020 remarks that a person educated in one's language, culture, and traditions is not a detriment but indeed a huge benefit to educational, social, and technological advancement. Understanding the relevance of mother tongue as the medium of learning for linguistic minority groups, government of Odisha has introduced Multi Lingual System of Education as a pilot basis from 2006-07 with a view to achieve equitable quality education. To know the ground realities of MLE programme for Juanga learners in terms of classroom process, assessment process and achievement levels the present study was undertaken. The present study comes under the purview of cross-sectional research design and undertaken through case study approach. Through purposive sampling technique the researcher selects one MLE and one NonMLE school from Banspal block of Keonjhar district in Odisha. From these schools all class-III tribal learners and all the teachers were selected purposefully and incidentally respectively. Three self made tools i.e. Classroom Observation Schedule, Achievement Test (Juanga Language) and Achievement Test (Odia Language) were used in this study. The data was analysed and interpreted through qualitative data analysis technique, percentage analysis technique. The present study reveals that introduction of MLE in the tribal school has created a good classroom climate in the school so far as activeness of the learners, classroom management , and presentation of learning experiences is concerned. The achievement level in language is upto mark inMLE schools due to the effect of MLE programm.
\end{abstract}

Key words: Classroom Process, Learning Achievement, Multilingual Education

\section{Introduction}

The significance of language in our lives is incomparable. It is not just restrained to being a means of communicating one's thoughts and ideas to the rest, but has also become a tool for forging friendships, cultural ties as well as economic relationships. The Vision Document 2020, published by the School and Mass Education Department, Government of Odisha (2003) indicates that inappropriate language of instruction; imperfect teacher-pupil communication, unsuitable curricula and textbooks are the major stumbling blocks in the process of learning and high drop-out rate of tribal children. In this context education through mother-tongue based multilingual education (MTB-MLE) to the marginalized group is a successful model for protection of indigenous knowledge and culture of a state (Benson \& Kosonen, 2013). Recognizing the importance of language in the classrooms, the RCFCE Act, 2009 has rightly emphasized the use of mother tongue as medium of instruction as far as practicable under Section 29 (2). Similarly, NEP, 2020 remarks that a person educated in one's language, culture, and traditions is not a detriment but indeed a huge benefit to educational, social, and technological advancement. Understanding the relevance of mother tongue as the medium of learning for linguistic minority groups government of Odisha has introduced Multi Lingual System of Education as a pilot basis from 2006-07 with a view to achieve equitable quality education. Mother-tongue based MLE programme is benefitting 142132 tribal students belonging to 21 (Santali, Saura, Koya, Kui, Kuvi, Kishan, Oram, Munda, Juanga ,Bonda, Gadaba, Ho, Gondi, Paroja, Kharia, Didayi, Bhinjhal, Bhuiyan, Bhumia, Bhatra and Bhunjia) tribal language groups in 1485 schools spread across 17 tribal dominated districts (Anugul, Bargarh, Balasore, Dhenkanal, Ganjam, 
Gajapati, Kandhamal, Kalahandi, Koraput, Keonjhar, Malkangiri, Mayurbhanj, Nawarangpur, Nuapada, Rayagada, Sambalpur and Sundargarh) of the state like Odisha. These tribal students are imparted primary education in their mother tongue which helps them in better comprehension, increased participation and enhanced levels of learning (OPEPA, SC/ST Section, data as on 23.8.2021). So far as Keonjhar district of Odisha is concerned MLE programme has been implemented in three languages viz. Juanga, Santali, Ho. But question arises what is the ground realities of MLE in terms of classroom processes and achievement level of the learners?

\section{Rationale of the study}

MLE programme have beneficial effects on academic achievement of students (Thomas and Collier, 2002). The students studying in MLE schools of Odisha and Andhra Pradesh are performing better in the curricular domains of language, environmental studies (EVS) and mathematics; and their participation level is higher (Panda, Mohanty, Nag \& Biswabandan, 2011). The observation of classroom practices of MLE schools of Gajapati district of Odisha revealed that, use of children's home language 'Saura' in the classroom transaction, eradicates 'school anxiety or fear' among the saura learners (Nag, 2018). MLE intervention in Keonjhar district, Odisha resulted that MLE programme has a positive impact on enrolment rates, decreased dropout rates, raised community awareness and participation in education (UNICEF, 2008). Though various research studies have been conducted by different researchers, but no comparative study yet been conducted on classroom processes of MLE and Non-MLE schools in terms of introduction of lesson, presentation of lesson, participation of students, use of TLM and classroom management by the teachers; and comparison of learning achievement in Language (Juanga) through school records and administration of self made test. So, taking into account the above research gap, the researcher felt worthwhile to conduct this study.

\section{Objectives of the study}

1. To study the classroom processes of MLE and Non-MLE schools with reference to introduction of lesson, presentation of lesson, participation of students, use of TLM and classroom management by the teachers.

2. To study the evaluation process followed in MLE and Non-MLE schools.

3. To study learning achievement of MLE and non-MLE school students with reference to Language subject.

\section{Research questions of the study}

1. How does the classroom processes of MLE and Non-MLE schools are effective and differs with reference to introduction of lesson, presentation of lesson, participation of students, use of TLM and classroom management by the teachers?

2. What assessment strategies are adopted by MLE and Non-MLE school teachers to assess the students learning progress?

3. How far the achievement in Language subject is satisfactory and valid in MLE and non-MLE school?

\section{Methodology of the study}

Research Design: The present study comes under the purview of cross-sectional research design and undertaken through case study approach.

Sample: Through purposive sampling technique the researcher selected one MLE and one Non-MLE school from Banspal block of Keonjhar district in Odisha. From the MLE school all the class-III learners and from Non-MLE school all the class-III tribal learners were selected purposefully. Similarly, all the teachers of these schools were also selected incidentally.

Tools and techniques: The following three self made tools were used in this study. 
- Classroom Observation Schedule: This schedule contains 5 components i.e. introduction of lesson, presentation of lesson, participation of students, use of TLM and classroom management by the teachers. The items of this schedule desire both close ended and open ended answers.

- Achievement Test (Juanga Language): An achievement test in Juanga Language containing 40 marks covering both objective and subjective items was prepared. This test paper contains space for students answer.

- Achievement Test (Odia Language): An achievement test in Odia Language containing 40 marks covering both objective and subjective items was prepared. This test paper contains space for students answer.

Data Analysis techniques: The collected data was analysed and interpreted through qualitative data analysis technique, percentage analysis technique. Similarly the collected data also triangulated to draw a valid conclusion.

\section{Discussion of the result}

\section{Classroom processes of MLE and Non-MLE school}

Process of introduction of lesson by the teachers: From classroom observation and interview with students it was found that in MLE school the teachers (both MLE \& Non-MLE) were checking the student's homework, asking previous knowledge testing questions, telling different stories and showing pictures, charts, images etc before introducing the topic where as in Non-MLE school the teachers introduced the lesson directly by reading the text books without going through student's homework or using teaching learning materials. It indicates in MLE school both MLE \& Non-MLE teachers are using inclusive pedagogy at the time of introducing lesson and the process of introducing lesson is better in MLE school than Non-MLE school.

Process of presentation of lesson by the teachers: Observation of the classroom process revealed that, the MLE School teachers were presented the lesson: using play way method, role play method, activity based method and followed by oral discussion. Meaning of the difficult words are also written on the blackboard and pronounced clearly by the teachers whereas in Non-MLE school teachers were presented the lesson by reading the textbooks. Meaning of the difficult words, important points of the topic are also written on the blackboard. In few observations it was found that the non-MLE school teachers used role play method for presenting the topic. It indicates the way of presentation of lesson by teachers in MLE school is better than their Non-MLE school counterparts.

Process of student participation: In MLE school maximum students were participated in teaching learning process in terms of answering teacher's questions, asking questions to the teachers, discussing with each others, raising their hands to answer, giving examples from their own culture etc. due to the effect of their mother tongue (Juanga) whereas in Non-MLE school a few number of tribal students were participated in teaching learning process as the medium of teaching learning process was Odia language. It indicates mother tongue based MLE programme increases students participation in classroom.

Process of TLM use: It was found that both MLE and Non-MLE school teachers were used general teaching aids in each and every class. Mostly teachers were used charts/pictures to explain the topic to the students rather than real objects or resources from the local community. It indicates no difference is found in terms of TLM use among MLE and Non-MLE school teachers.

Process of classroom management: The MLE school teachers were maintaining discipline by involving the learners in different activities like asking students to tell the story or recite the poem; making teaching interesting through humors etc. Whereas in non-MLE school, as the teachers did not check or monitors student's activities in the class, sometimes students were indiscipline. It occurs as the teachers were involved in other school activities assigned by the head masters.

\section{Assessment process of MLE and Non-MLE school}

In the MLE school classroom process it was observed that the teacher asked different questions to the students, tried to explore personal learning difficulties of the students, facilitates peer assessment strategy 
and also provides reinforcement \& feedback to the students. But in Non-MLE school teachers were only bothering to complete the syllabus. In indicates in MLE school the teachers were used formative, and diagnostic techniques to assess their learners whereas it was not found in Non-MLE school.

\section{Learning achievement level of MLE and Non-MLE school tribal learners}

Analysis of previous examination records: Learning Achievement of Class-III students in language paper (100 marks) for the academic session (2019-20) is presented below:

Table-1

\begin{tabular}{|l|l|l|l|l|l|l|}
\hline $\begin{array}{l}\text { Marks Scored } \\
\text { in \% }\end{array}$ & $\begin{array}{l}\text { Below } \\
\mathbf{3 0 \%}\end{array}$ & $\mathbf{3 0 - 4 5 \%}$ & $\mathbf{4 5 - 6 0 \%}$ & $\mathbf{6 0 - 8 0 \%}$ & Above 80\% & $\begin{array}{l}\text { Total No of } \\
\text { Students (N) }\end{array}$ \\
\hline $\begin{array}{l}\text { No and \% of } \\
\text { MLE school } \\
\text { students }\end{array}$ & $3(12 \%)$ & $5(20 \%)$ & $4(16 \%)$ & $7(28 \%)$ & $6(24 \%)$ & $25(100 \%)$ \\
\hline $\begin{array}{l}\text { No and \% of } \\
\text { Non- MLE } \\
\text { school tribal } \\
\text { students }\end{array}$ & $9(30 \%)$ & $7(23 \%)$ & $6(20 \%)$ & $5(17 \%)$ & $3(10 \%)$ & $30(100 \%)$ \\
\hline
\end{tabular}

It is clear from the above table that the achievement level in MLE school is high in comparison to NonMLE school as more percentage of students secured above $60 \%$ mark in MLE schools and vice versa.

Analysis of self-made test administration result: Learning Achievement of Class-III students in language paper (40 marks) obtained by administration of self made test is presented below:

Table-2

\begin{tabular}{|l|l|l|l|l|l|l|}
\hline $\begin{array}{l}\text { Marks Scored } \\
\text { in \% }\end{array}$ & $\begin{array}{c}\text { Below } \\
\mathbf{3 0 \%}\end{array}$ & $\mathbf{3 0 - 4 5 \%}$ & $\mathbf{4 5 - 6 0 \%}$ & $\mathbf{6 0 - 8 0 \%}$ & Above 80\% & $\begin{array}{l}\text { Total No of } \\
\text { Students (N) }\end{array}$ \\
\hline $\begin{array}{l}\text { No and \% of } \\
\text { MLE school } \\
\text { students }\end{array}$ & $4(16 \%)$ & $5(20 \%)$ & $3(12 \%)$ & $6(24 \%)$ & $7(28 \%)$ & $25(100 \%)$ \\
\hline $\begin{array}{l}\text { No and \% of } \\
\text { Non- MLE } \\
\text { school tribal } \\
\text { students }\end{array}$ & $9(30 \%)$ & $6(20 \%)$ & $7(23 \%)$ & $5(17 \%)$ & $3(10 \%)$ & $30(100 \%)$ \\
\hline
\end{tabular}

It is clear from the above table that the achievement level in MLE school is high in comparison to NonMLE school as more percentage of students secured above $60 \%$ mark in MLE schools and vice versa.

From both table-1 and table-2 it is clear that MLE school student's achievement level is better than nonMLE school students in language subject and previous examination result is valid one. It is due to the positive impact of mother tongue based MLE programme.

\section{Findings of the Study}

- The MLE school teachers introduced lesson very effectively in terms of telling stories, showing TLMs, testing student's previous knowledge etc. than Non-MLE school teachers.

- The way of presentation of lesson by MLE school teachers is better than Non-MLE school teachers as the MLE School teachers are using play way method, role play method, activity based method and followed by oral discussion at the time of presenting lessons.

- Mother tongue based MLE programme increases students participation in classroom. 
- No difference is found in terms of TLM use among MLE and Non-MLE school teachers.

- As the MLE school teachers involved their learners in different activities like asking students to tell the story or recite the poem and making teaching interesting through humors, so MLE school students are more disciplined.

- In MLE school the teachers are using formative, and diagnostic techniques to assess their learners, whereas it is not found in Non-MLE school.

- MLE school student's achievement level is better than non-MLE school students in language subject due to the positive impact of mother tongue based MLE programme.

\section{Conclusion}

The present study reveals that introduction of MLE in the tribal school has created a good classroom climate in the school so far as activeness of the learners, classroom management, and presentation of learning experiences is concerned. The achievement level in language is upto mark in MLE schools due to the effect of MLE programm. Hence, government of Odisha may arrange some special classes for the tribal learners reading in Non-MLE schools to ensure equity in education, give social justice to the tribal, protect indigenous knowledge and culture, success of Samagra Siksha Abhijan, safeguard humanism in man, and long live of democracy.

\section{References}

1. Benson, C. \& Kosonen, K. (Eds.) (2013). Language issues in comparative education: Inclusive teaching and learning in non dominant languages and cultures. Rotterdam: Sense Publishers.

2. Government of India (2009). Right of Children to Free and Compulsory Education Act, 2009.

3. Govt. of Orissa (2003). Vision 2020, School and Mass Education Department, Bhubaneswar, Orissa.

4. MHRD (2020). National Education Policy. Ministry of Human Resource Development, Govt. of India.

5. Nag, Shivani (2018). Transformative Potentials of Multilingual Education Models in Odisha, India. European Journal of Educational Studies, Vol. 4(4), pp.320-338.

6. Orissa Primary Education Programme Authority (OPEPA). n.d. Multi-lingual Education for Tribal Children of Orissa. Bhubaneswar: OPEPA. Retrieved from http://opepa.odisha.gov.in/website/SCSTEdu3.aspx on dt. 20.7.2021.

7. Panda, M., Mohanty, A. K., Nag, S., and Biswabandan, B. (2011). Does MLE work in Andhra Pradesh \& Odisha? A longitudinal study. Swaral (6-7), pp. 2-23. Retrieved from http://nmrcjnu.com/nmrc_img/Newsletter\%20issue\%206\%20\&\%207.pdf on dt. 24.7.2021.

8. Thomas, W. P., \& Collier, V. (2002). A national study of school effectiveness for language minority students' long-term academic achievement. Santa Cruz, CA and Washington, DC: Center for Research on Education, Diversity \& Excellence. Retrieved from http://www.crede.ucsc.edu/research/llaa/ 1.1_final.html. on dt. 24.5.2021.

9. UNESCO, (2008). Improving the Quality of Mother Tongue-based Literacy and Learning: Case Studies from Asia, Africa and South America. Bangkok: UNESCO. 